\title{
Correction to: Trastuzumab administration during pregnancy: an update
}

\author{
Angeliki Andrikopoulou 1,2, Kleoniki Apostolidou, 1,2, Spyridoula Chatzinikolaou², Garyfalia Bletsa ${ }^{3}$, \\ Eleni Zografos ${ }^{1,2}$, Meletios-Athanasios Dimopoulos ${ }^{1,2}$ and Flora Zagouri ${ }^{1,2^{*}}$
}

\section{Correction to: BMC Cancer 21, 463 (2021) https://doi.org/10.1186/s12885-021-08162-3 \\ Following publication of the original article [1], the authors identified reference citation errors in Table 1. The corrected Table 1 is supplied below.}

\section{Author details}

'Department of Clinical Therapeutics, Alexandra Hospital, Medical School, 11,

,528 Athens, Greece. ${ }^{2}$ Medical School, National and Kapodistrian University

of Athens, Athens, Greece. ${ }^{3}$ Hellenic Anticancer Institute, Athens, Greece.

Published online: 17 December 2021

\section{Reference}

1. Andrikopoulou A, Apostolidou K, Chatzinikolaou S, et al. Trastuzumab administration during pregnancy: an update. BMC Cancer. 2021;21:463. https://doi.org/10.1186/s12885-021-08162-3.

${ }^{2}$ Medical School, National and Kapodistrian University of Athens, Athens, 


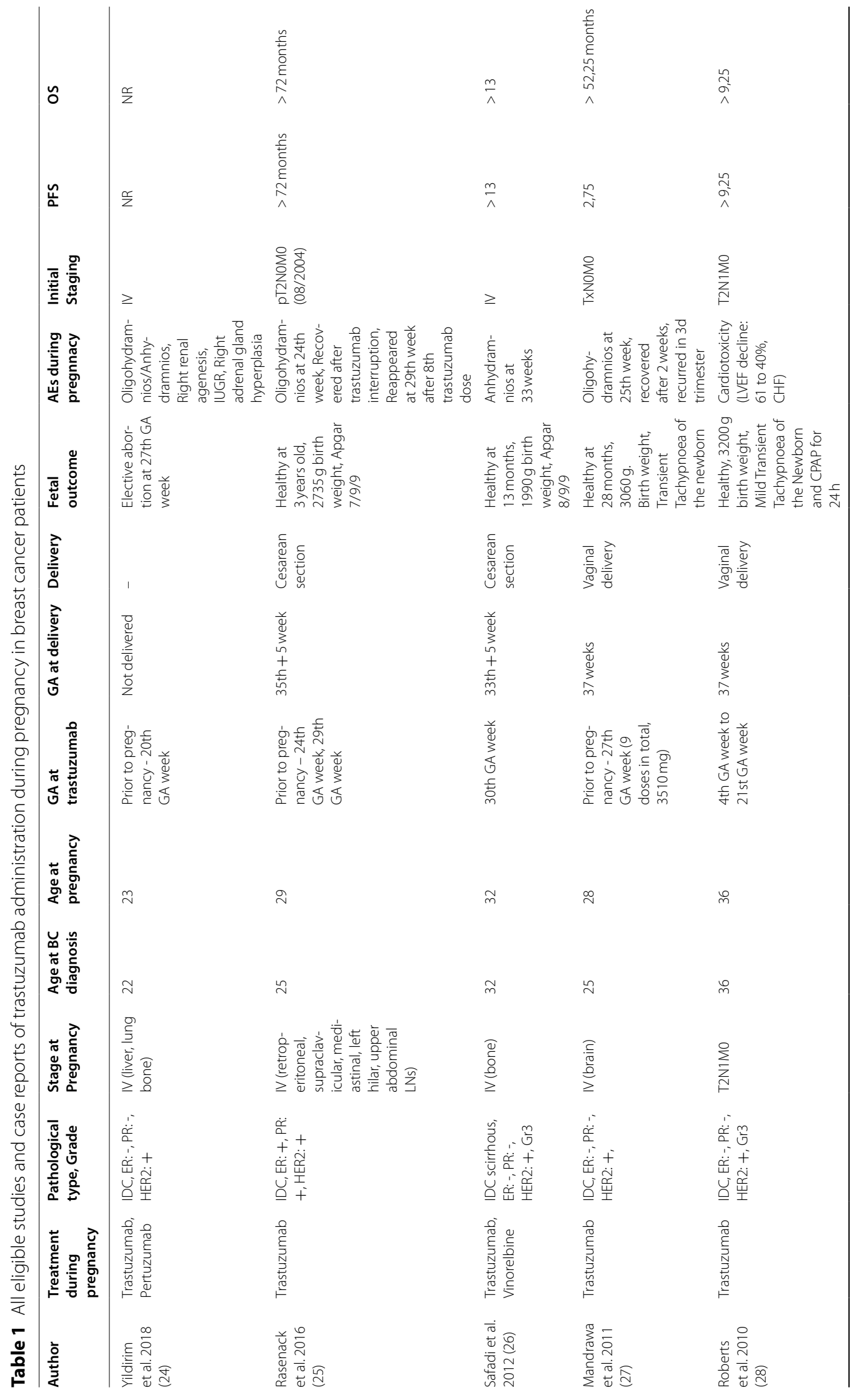




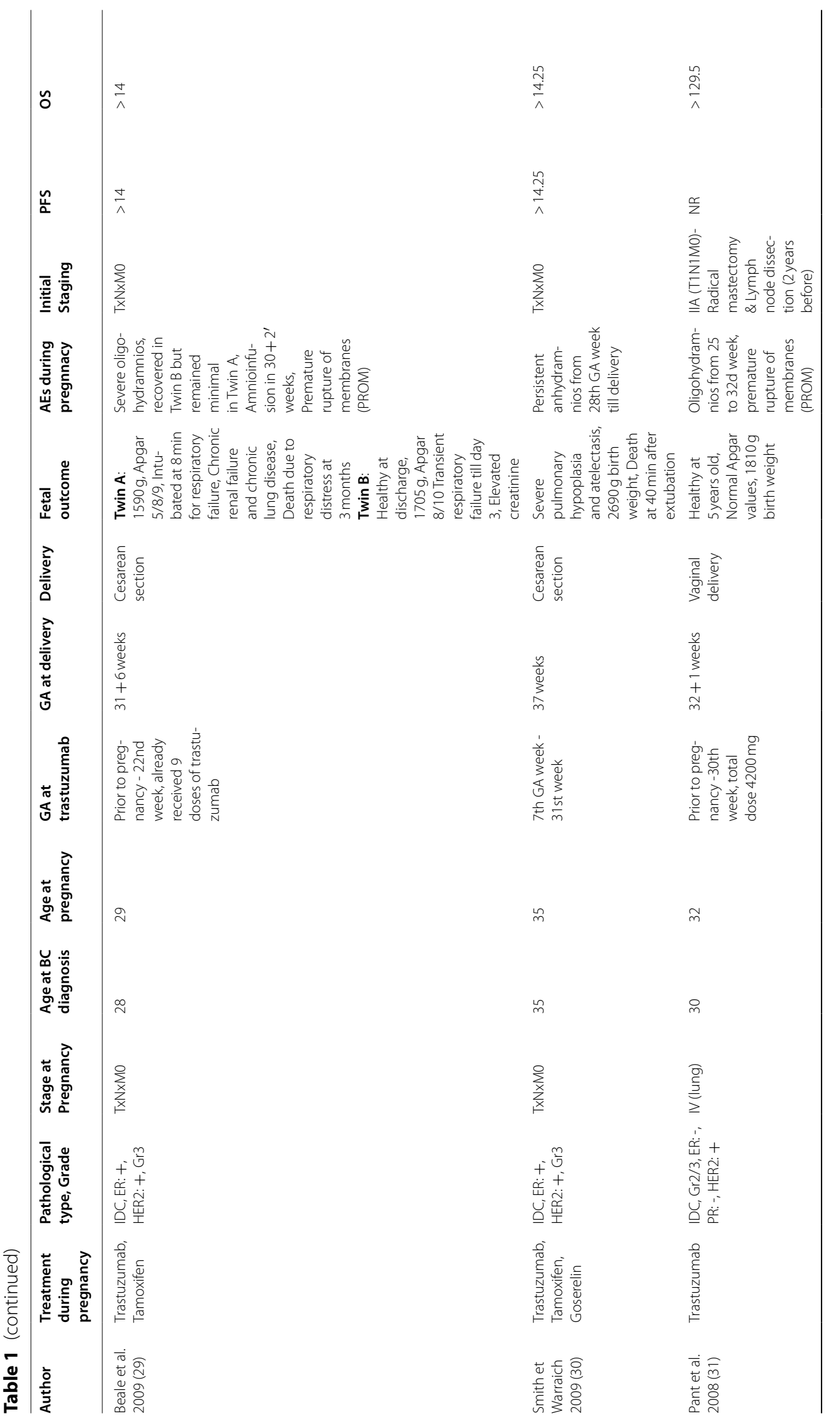




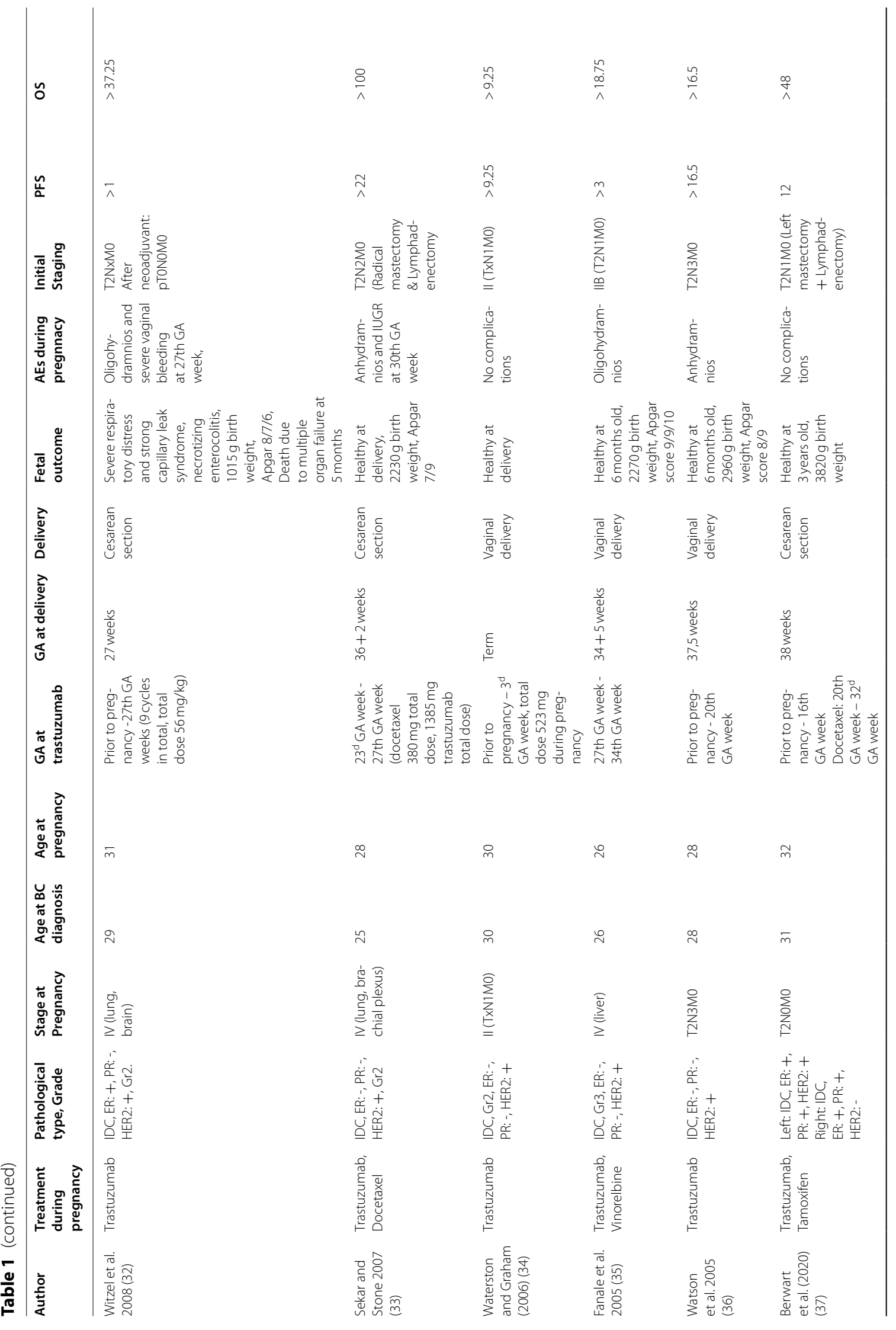




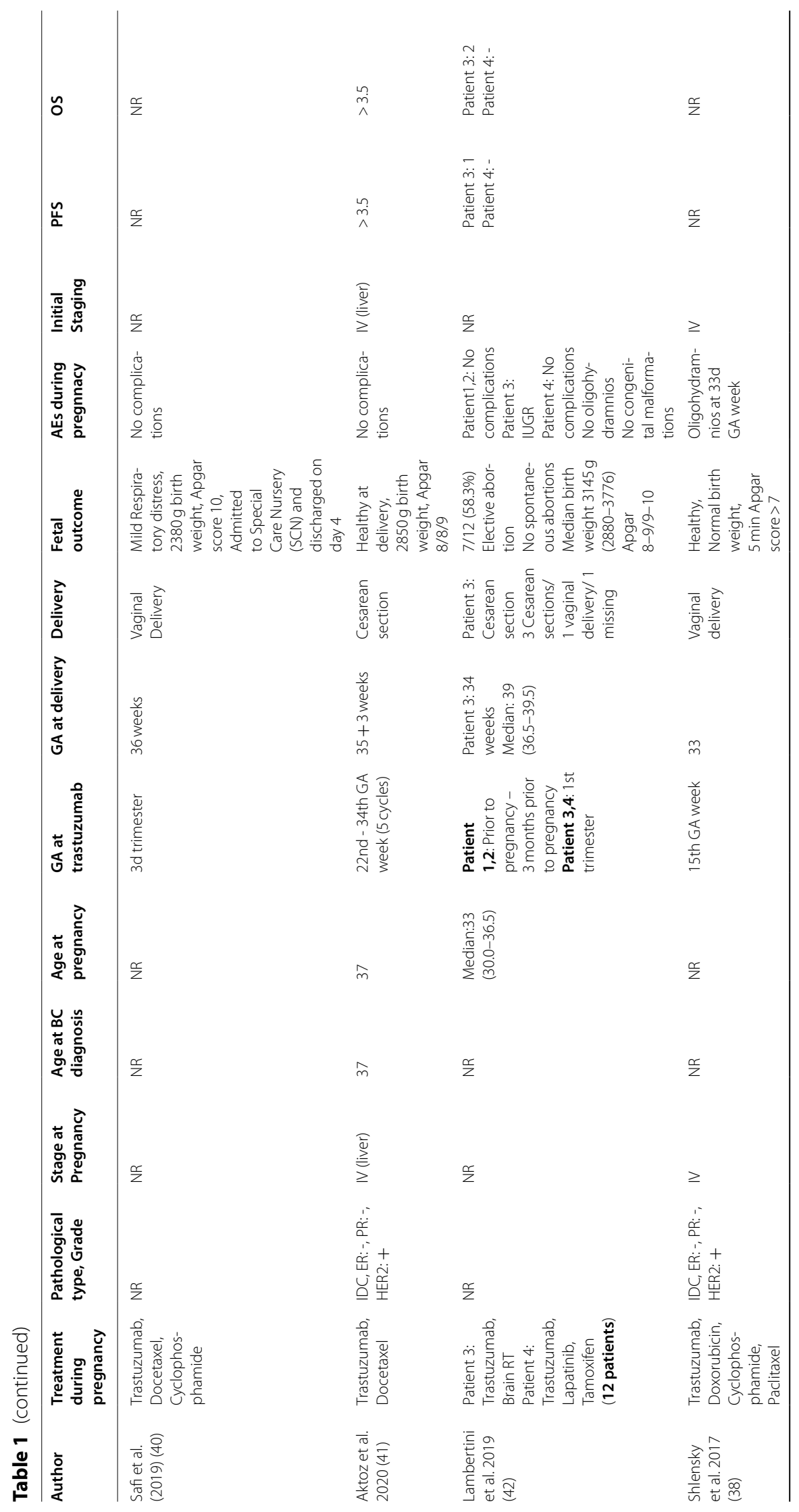




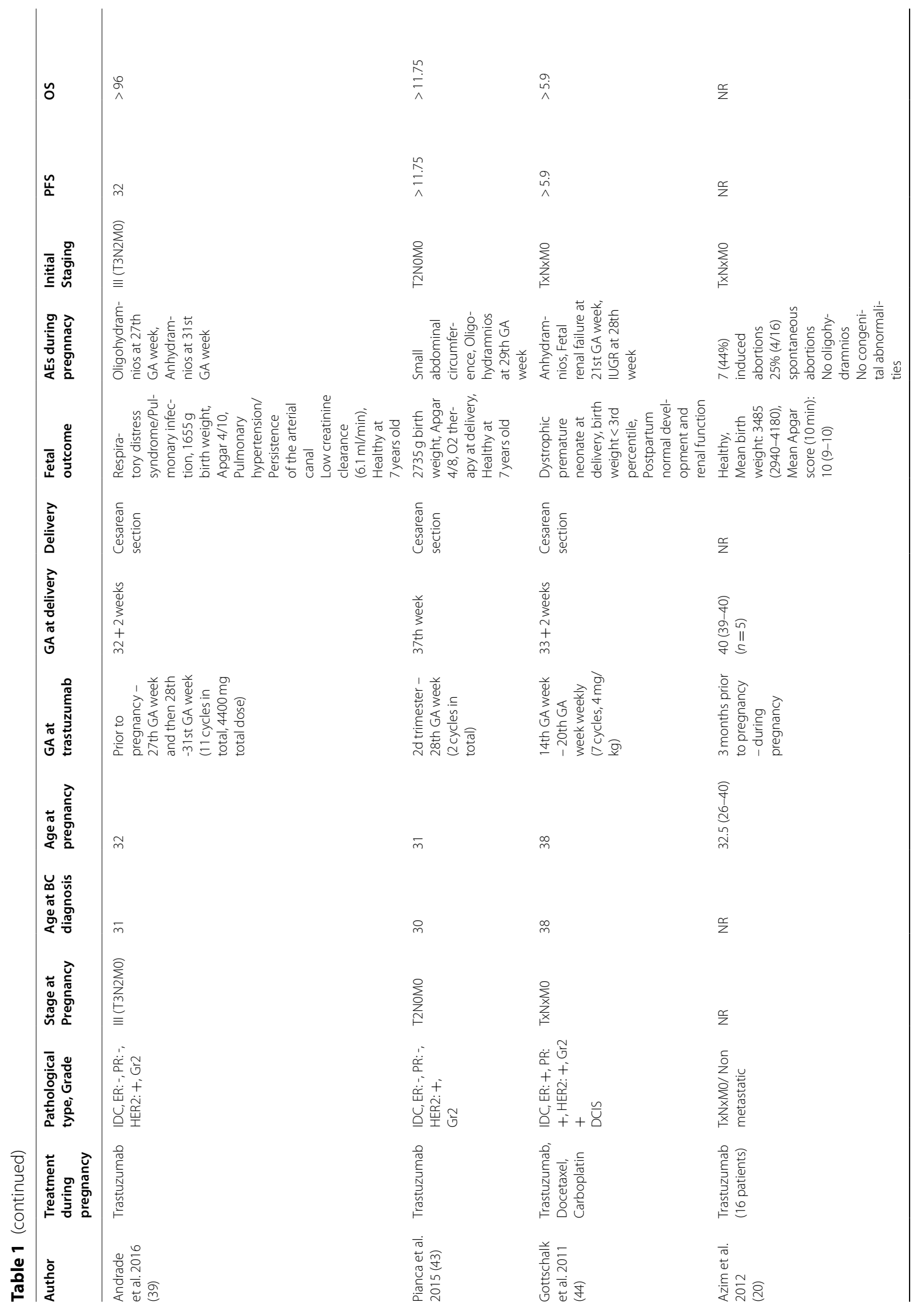




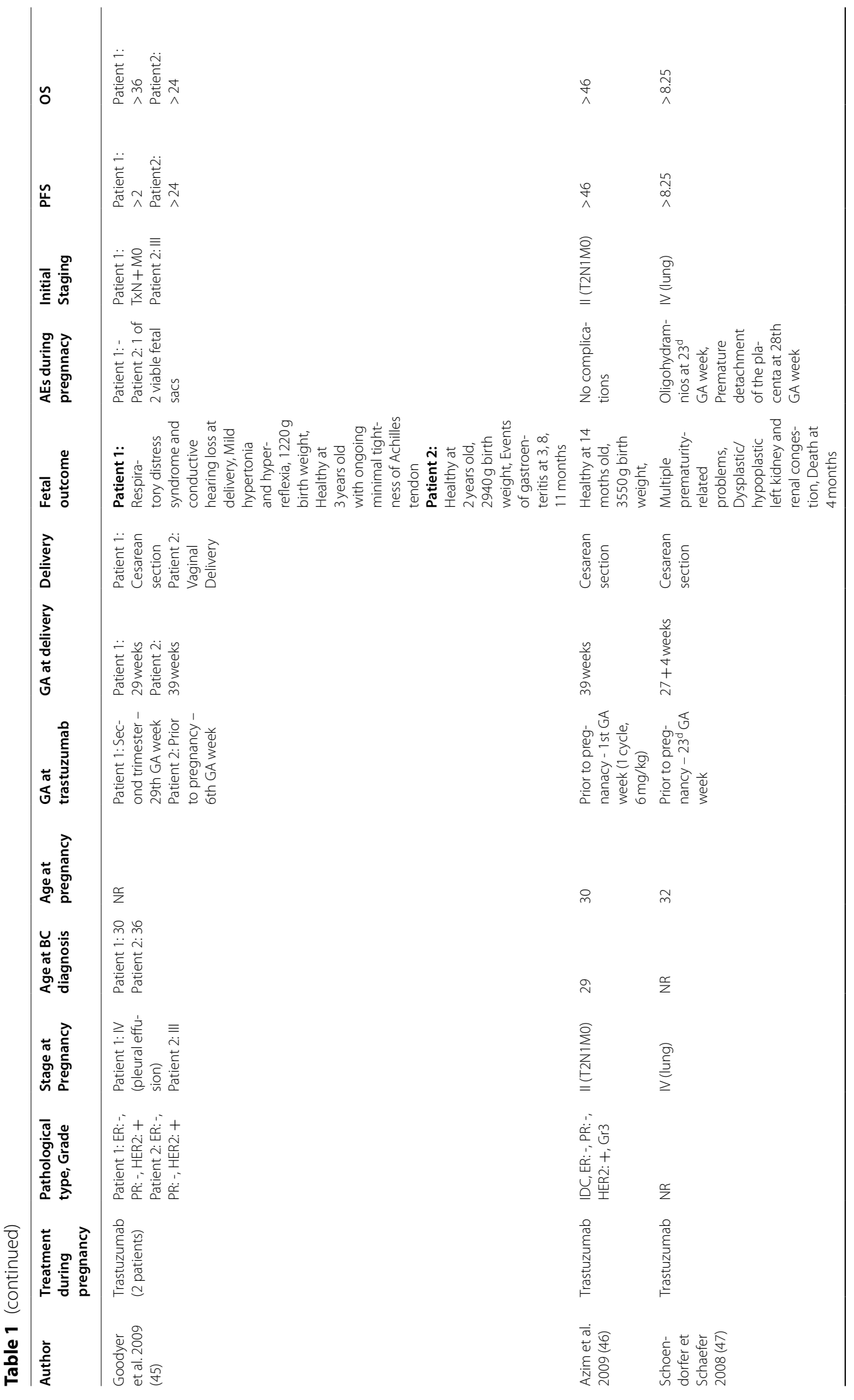




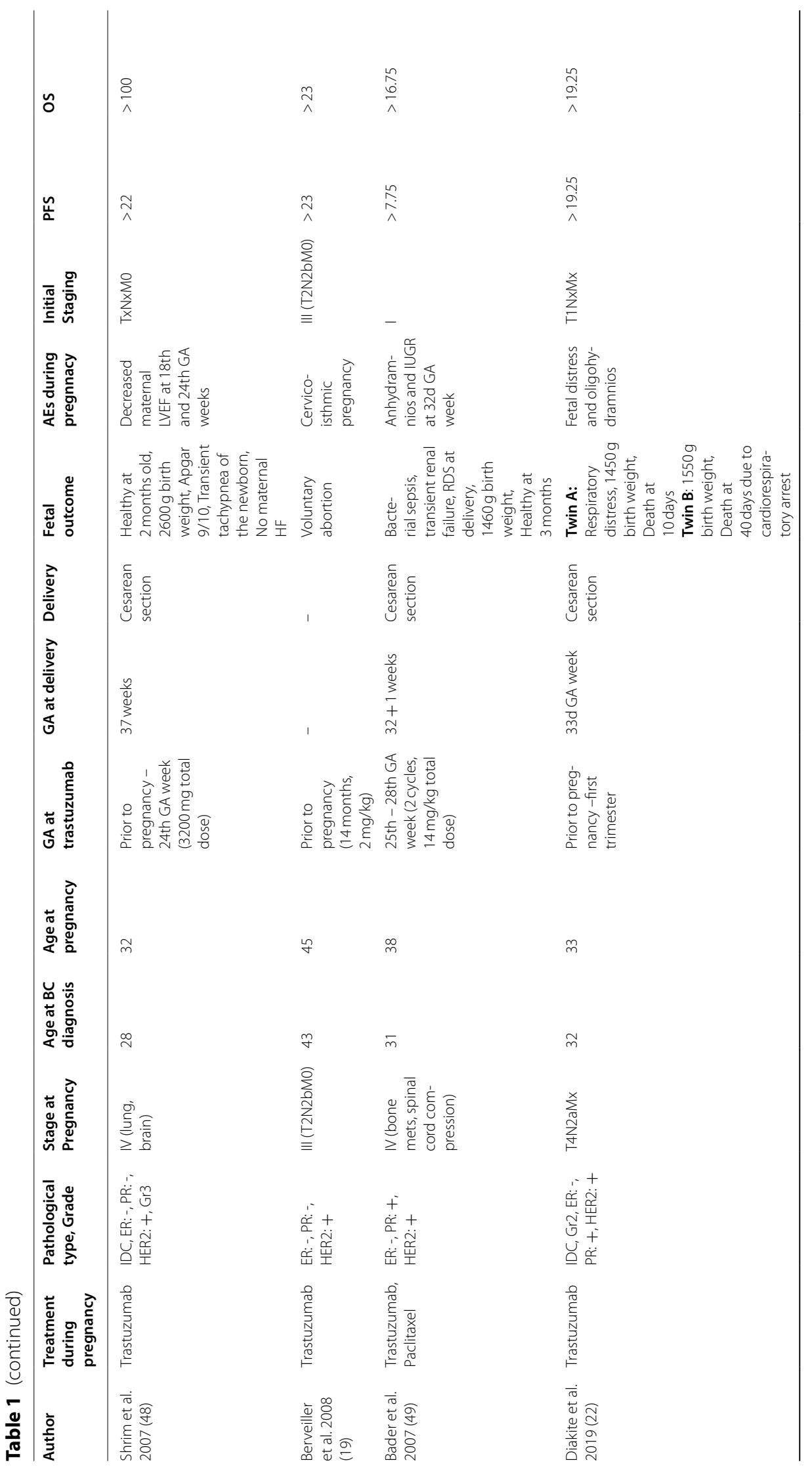




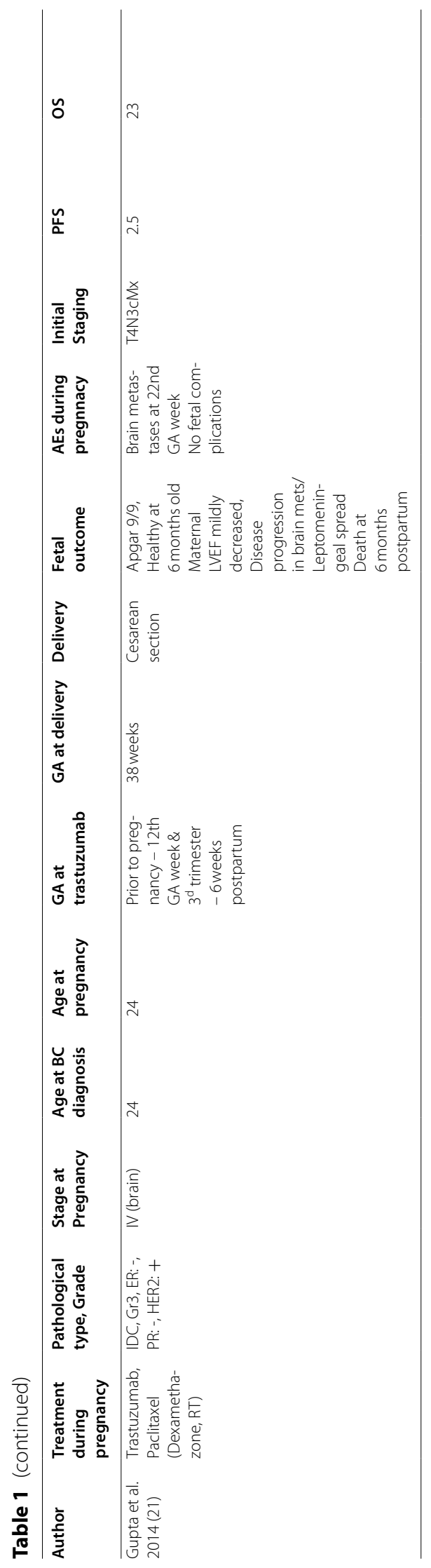

